\title{
Breaking Down The Barriers To Organizational Change
}

Stuart Rosenberg, Monmouth University, USA

Joseph Mosca, Monmouth University, USA

\begin{abstract}
A significant failure rate exists when it comes to organizational change. Managers understand the importance of organizational change, but many of them do not know how to execute it effectively. This study examines the reasons why the implementation of organizational change is so complicated and it suggests ways to break down the barriers to change.
\end{abstract}

Keywords: organizational change models; resistance to change; change strategy

\section{INTRODUCTION}

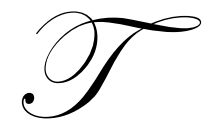

here has been a profusion of research on organizational change and yet, many firms have struggled to achieve the changes that they have sought to implement. Beginning with the seminal 3-step change model developed by Lewin (1951), where firms were instructed to undertake change by first preparing the organization for change ("unfreezing"), then engaging the organization in the change ("movement"), and finally anchoring new methods into the organization's culture ("re-freezing"), critics were quick to condemn it for being overly simplistic. Kotter (1996) developed a more involved approach with his popular 8-step change model, incorporating elements such as leadership and employee involvement, but the strategies espoused by this and essentially all other change models have not translated consistently into successful implementation.

Estimates show that there is a 70 percent failure rate when it comes to organizational change (Maurer, 2010). Clearly, the problem is not a dearth of models; rather, it is important to recognize that some firms are better designed for implementing change; and as a result, they can do a better job of overcoming the barriers to change that exist in so many other firms. There have been a number of management case studies written on firms, like GM and Xerox, who have been slow to change in a dynamic environment, while others have been written on firms, like Apple and Netflix, who have made innovation a cornerstone of their business models.

As business strategies have become more complex, leadership entails more than the ability to inspire individuals and guide the work of teams. The problem, according to Getz, Jones, and Loewe (2009), is that strategy is easy, but execution is hard. While poor strategies cannot deliver good results, good strategies that are poorly implemented are also unlikely to achieve good results. This study examines the various reasons why execution of change strategy is so difficult and it offers a number of suggestions to break down some of the barriers to change in order to facilitate organizational change.

\section{LITERATURE REVIEW}

Over the last few decades, firms routinely have needed to deal with environmental factors such as rapid technological change, economic uncertainty, industry growth and decline, increased global competition, and major shifts in demography and values. In the face of such complex conditions, many of our ways of managing change are no longer appropriate. During these times, attempts to resist change by restoring order may not only be fruitless, but actually damaging (Barczak, Smith, and Wilemon, 1987).

Self and Schraeder (2009) stated that for the sake of survival, some firms have attempted to anticipate or respond to these changes through strategies including organizational redesign, which often embodies changing the 
very culture of the organization. Those firms that fail to adapt or respond to these changes in a timely fashion run the risk of losing market share, losing key employees, jeopardizing shareholder support, and possibly even demise. Consequently, while Self and Schraeder maintain that the first challenge that firms face is recognizing the need for change, the second, and possibly more significant, challenge that firms face is effectively organizing strategies to implement change.

Getz, Jones, and Loewe (2009) prescribe building a migration path from the point of identifying the need for change to some future desired state based on the evolution of the firm within its competitive landscape. Such a migration path needs to identify the major gaps between today and the future state, since an obvious trigger for change occurs whenever there is a gap in organizational performance. The path also needs to select the appropriate gap-closing action steps, organize the steps by division or strategic business unit, and sequence the steps as efficiently as possible. Kesler and Kates (2010) argue that firms need to build a compelling case for change, to rely on HR to maintain objectivity and provide integration for actionable steps, and to think beyond solving near-term problems. They also argue, however, that there might be certain circumstances where a "pull the band-aid off fast" approach might be warranted, especially when strategic choices are clear and competitive pressures make it critical to move quickly.

Notwithstanding this awareness about the need for change and the need to deploy a suitable change strategy, barriers to change continue to present significant obstacles for a wide range of organizations, from multinational corporations with thousands of employees to small firms with fewer than 100 employees. But why?

In recent years, there has been considerable research (Alas, 2007; David, 2006; Denning, 2005; Karim and Kathawala, 2005; Gill, 2003; Rogers, 2003; Sims, 2002; Trader-Leigh, 2002; Habeck et al., 2000; Zorn et al., 1999, Connor, 1993; and Haveman, 1993; and others) that has attempted to explain the reasons why organizations resist change. Unfortunately, as Werkman (2009) reminds us, although scholars are unanimous about the significance of the failure rate regarding organizational change, there is no such unanimity as to its causes. Table 1 shows a list of the major reasons for the resistance to change based on a review of the existing literature. The twenty items reflected in the table can be grouped as follows: 1 through 8 are largely personal factors for resistance, 9 through 18 are largely organizational factors for resistance, and 19 and 20 are factors that are specific to the change itself.

Hultman (1995) indicated that the types of resistance listed- particularly those based on personal factorsare revealed in two dimensions: active and passive. Active resistance includes behaviors such as being critical, selective use of facts, sabotaging, and starting rumors. Passive resistance includes behaviors such as supporting a change publicly but failing to implement it, procrastinating, and withholding information.

Of course, the behavior of senior managers themselves can be the source of the problem. As Schaffer (2010) points out, these behaviors are often difficult to recognize and correct because they protect egos. This can be manifested in many ways, including a failure to spell out credible plans, excusing subordinates from the pursuit of change goals by allowing them to be preoccupied with their own units, colluding with experts by going along with flawed plans, and standing by while associates overprepare.

Gilley, Godek, and Gilley (2009) explain that resistance to change can occur because organizations possess powerful immune systems, much in the same way that immunities develop in the human body. These systems defend the status quo and resist things that they do not recognize as their own self. Therefore, just as the human body will reject viruses and bacteria, organizations will erect barriers in the form of the people, policies, procedures, and culture it develops to prevent change. 
Table 1: Reasons For Resistance To Organizational Change

\begin{tabular}{|r|l|}
\hline 1 & Employees' attitudes/disposition toward change \\
\hline 2 & Fear of the unknown (uncertainty) \\
\hline 3 & Lack of understanding of the firm's intentions \\
\hline 4 & Fear of failure \\
\hline 5 & Disruption of routine \\
\hline 7 & Increased workload (due to downsizing or employees leaving voluntarily/involuntarily) \\
\hline 8 & Pack of rewards for implementing change \\
\hline 9 & Poor leadership \\
\hline 10 & Dysfunctional organizational culture \\
\hline 11 & Organizational size and rigidity \\
\hline 12 & Lack of management support for the change (organizational commitment) \\
\hline 13 & Lack of trust between management and employees \\
\hline 14 & Inability or unwillingness of management to deal with resistance \\
\hline 15 & Lack of participation due to top-down steering \\
\hline 16 & Organizational politics/conflict \\
\hline 17 & Internal conflict for resources \\
\hline 18 & Lack of consequences for inadequate or poor performance \\
\hline 19 & The content of the change (an ill-conceived change/relevance of the goals of change) \\
\hline 20 & Poor implementation planning \\
\hline
\end{tabular}

The organization's history, too, can serve as a barrier to change. Brunninge (2009) remarks that organizational history is a critical part of the strategy process, but once it has occurred, it is fixed and cannot be altered. Therefore, historically embedded paradigms can result, causing inertia within the organization. Brunninge argues that the purposeful use of history can be a powerful tool for managers to influence organizational change processes, but for firms with a track record of failed change attempts the use of organizational history is likely to be viewed by employees with cynicism and suspicion.

\section{METHODOLOGY}

This study took place at the graduate business schools of two universities, one in New Jersey and the other in Washington. All the participants were employed, and a broad range of organizations were represented, both large and small, in the private sector and the public sector. There were 246 participants who responded over the course of the last few years to a series of ten questions that addressed their experience with organizational change, with the most recent participants responding in Fall 2010. The vast majority of the participants were in their twenties or early thirties. It can be concluded that most of them were either entry level employees, first line supervisors, or possibly middle managers, but certainly higher level managers were not a part of the population. A questionnaire was distributed to the participants in a classroom and it was anonymous.

The ten questions were as follows:

1. Have you ever been part of an organization change?

2. Was the change explained to you?

3. Were your needs considered?

4. Were all employees' needs considered? 
5. Did the employees accept the change?

6. Did the change have a schedule?

7. Did the employees witness the change as it took place?

8. Were employees empowered to help the change?

9. Was the change implemented?

10. Did the change fail?

The responses to each of the questions were tabulated, with any of the surveys with a "No" response for question 1 removed from the tabulations for the remaining questions. The objective of the researchers was to assess the responses in the context of the literature on resistance to organizational change and to ultimately allow for conclusions to be drawn concerning possible remedies.

\section{FINDINGS}

The results of the questionnaire are reflected on Table 2. Note that 207 participants (i.e., 246 minus 39) were able to respond to questions 2 through 9 and on certain questions (particularly question 10), some of the participants elected not to respond.

Table 2: Change Management Survey: Raw Data

\begin{tabular}{|c|c|c|c|c|c|c|}
\hline Quest. & & YES & Percent & $\mathrm{NO}$ & Percent & TOT \\
\hline 1 & Have you ever been part of an organization change? & 207 & $84.2 \%$ & 39 & $15.8 \%$ & 246 \\
\hline 2 & Was the change explained to you? & 161 & $78.2 \%$ & 45 & $21.8 \%$ & 206 \\
\hline 3 & Were your needs considered? & 97 & $46.9 \%$ & 110 & $53.1 \%$ & 207 \\
\hline 4 & Were all employees' needs considered? & 60 & $29.0 \%$ & 147 & $71.0 \%$ & 207 \\
\hline 5 & Did the employees accept the change? & 82 & $39.6 \%$ & 125 & $60.4 \%$ & 207 \\
\hline 6 & Did the change have a schedule? & 109 & $52.7 \%$ & 98 & $47.3 \%$ & 207 \\
\hline 7 & Did employees witness the change as it took place? & 117 & $57.6 \%$ & 86 & $42.4 \%$ & 203 \\
\hline 8 & Were employees empowered to help the change? & 94 & $45.9 \%$ & 111 & $54.1 \%$ & 205 \\
\hline 9 & Was the change implemented? & 145 & $71.4 \%$ & 58 & $28.6 \%$ & 203 \\
\hline 10 & Did the change fail? & 53 & $26.9 \%$ & 144 & $73.1 \%$ & 197 \\
\hline
\end{tabular}

The fact that 84 percent of the participants were part of an organization that underwent a change (question 1 ) is not surprising, given the fact that most organizations find it a necessity to formulate change strategies with some regularity in order to remain viable in the competitive environment.

It is encouraging to see that 78 percent of the participants felt that the change was explained to them (question 2). Perhaps one might expect that the response to this question should be 100 percent, but based on the literature it appears that there is a considerable breakdown in communicating change strategy throughout an organization. Nonetheless, it's a good sign here that the participants felt they were not in the dark concerning their organization's change.

The percentages of participants who responded "Yes" dropped precipitously on the next two questions. Less than half of the participants felt that their needs were considered with regard to the change strategy, and less than a third felt that the needs of all employees in the organization were considered (47 percent and 29 percent on questions 3 and 4, respectively). These responses would suggest that resistance to the changes might become an issue for the organizations trying to implement them.

Similarly, the responses to question 5 appear to support the literature and potentially create a problem for change managers, as only 40 percent of the participants indicated that the employees of their organizations went along with the change. 
Slightly more than half the participants indicated that the change had a schedule and that employees witnessed the change as it was taking place (53 percent and 58 percent on questions 6 and 7, respectively), but clearly, these percentages imply that there was considerable room for improvement with regard to the execution of the changes.

Less than half of the participants (46 percent) felt that employees were empowered to help implement the change (question 8). A lack of empowerment dovetails with several of the personal and organizational factors on the list of reasons for resistance to organizational change in Table 1.

On the question where participants were asked whether the change was implemented (question 9), the percentage of affirmative responses climbed to 71 percent. However, this means that close to a third of the change strategies that had been formulated were ultimately scrapped by management.

For question 10, the participants appear to have responded relatively positive as group. Only 27 percent of the participants felt that the change that their organization took on actually failed, which is less than what the literature has to say about the rate of failure of organizational changes. The design of the survey was intentionally simple, but perhaps for this question more than any other it could have been beneficial to elicit more information in order to better understand the changes being evaluated as well as the participants' interpretation concerning failure. The point here, though, is that more than a quarter of the changes, however small they might have been, were seen as failures, which would not be an acceptable rate to management under any circumstances.

\section{DISCUSSION}

It is useful to look at the reasons for resistance to organizational change in Table 1 in conjunction with the responses to our survey in order to suggest ways to break down some of the barriers to organizational change.

Beginning with the barriers that are specific to the change itself (reasons 19 and 20) - the content of the change and poor implementation planning- these certainly can have a negative impact on several of the survey items. In particular, poor execution of the implementation plan has a direct link to the following items:

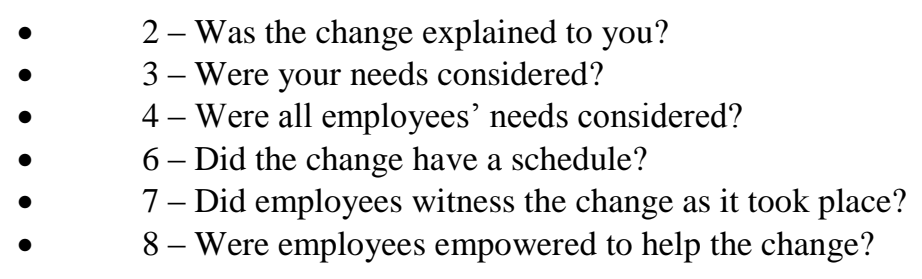

If organizations can take the right steps to strengthen the execution of their change strategies, then the odds of success for change will likely improve. Many factors can lessen resistance, including developing appropriate communications and employee involvement schemes, among others; but clearly there is no "one size fits all" generic approach that can serve as a quick fix for the diversity of organizations in need of change.

Any organization can gain valuable insight into potentially breaking down the barriers of change, however, by reviewing the organizational factors (reasons 9 through 18) in Table 1. Leadership, culture, structure, and the related organizational factors can undermine successful change. Above all, ensuring that organizational capabilities exist to bring about successful change is critical. Kesler and Kates (2010) argue that today's general managers understand the importance of organizational capabilities to compete, but many are less clear how to create them.

Werkman (2009) reported that large, bureaucratic organizations with mechanistic structures can hinder change through too much managerial power and too many rules and procedures. Communication is therefore less personal and more formal. Conversely, small organizations, or ones with greater flexibility, present other challenges for management to orchestrate change. Either way, management's ability to effectively communicate organizational change is essential to mitigate the personal reasons for resistance to change, such as fear of the unknown, lack of understanding, disruption of routine, perceived loss of security, etc. (reasons 1 through 8 in Table 1). 
Perhaps certain changes can be implemented in a piecemeal fashion rather than on a large scale. This could accomplish a couple of things. First, employees might perceive a change as less threatening. Second, if it is done incrementally and it doesn't seem to work, the risk of failure could be minimized.

There cannot be any resistance on the part of management in order for an organizational change to be successfully implemented (see reason 12 in Table 1). Too often this is the case. Management must be able to be persuasive; if their feelings are divided in any way, then change will likely fail. Self and Schraeder (2009) argue that not only must management demonstrate there is a need for change, but they also must provide information that the proposed initiative is the correct one.

Eaton (2010) states that people are more critical to change than process, and it is the responsibility of management to help the organization move from merely implementation to the point where improvements are fully embedded in the culture; in other words, create a culture of change.

Levin and Gottlieb (2009) remind us that organizational culture can either be an enabler or an obstacle to implementing change in organizations since culture, by definition, provides stability, continuity, and predictability to organizational life. As such, they argue that organizational leaders need to be the primary architects and sponsors of any cultural realignment; this is not likely work that can be delegated.

To create a culture of change, it is important for organizations to hire individuals who thrive in dynamic environments. Human resource managers ought to consider developing training programs that deal with change and to cultivate change skills throughout the organization.

McGuire and Rhodes (2009) maintain that a paradigm shift has taken place in the $21^{\text {st }}$ century, requiring a transformation of leadership culture. He and Baruch (2009) take a similar stance by calling for a transformation of organizational identity in order to enable organizational change. Sparrow and Ringland (2010) propose that organizations adopt a self-renewing framework in order to be prepared for the need for continuous organizational renewal. As stated earlier, these types of strategies are not necessarily new to the literature on organizational change. Armenakis, Harris, and Field (1999) designed a change model that focused specifically on the creation of readiness for change in order to counteract the sources of resistance.

Some of the sources of resistance alluded to in our survey can be ameliorated if management makes use of detailed strategies that incorporate change responsibilities into performance measurement. (Note that reason 7 in Table 1 was lack of rewards for implementing change.) If a change does entail an increased workload (reason 6 in Table 1), then the use of incentive compensation is clearly appropriate.

In summary, it is recommended that managers place more attention to 1) rooting the concept of change into an organization's culture, 2) hiring individuals who embrace the idea of working in a dynamic environment, and 3 ) adopting a variety of appropriate strategies aimed at breaking down the barriers to organizational change. It is fair to conclude that as a result, the role that managers play will likely become more complex. Bordum (2010) points out that a practical paradox can emerge between the time horizon inscribed in strategic management and the empirical demands to it under the pressures of high frequency change. The bottom line, however, is that based on the significant failure rate of organizational change, it is imperative that managers resort to adopting whatever change strategies work best for their organization. It is apparent that without executing these strategies, the barriers to organizational change may simply be too high.

\section{AUTHOR INFORMATION}

Dr. Stuart Rosenberg, Associate Professor of Management at the Leon Hess Business School, Monmouth University, earned an M.B.A. and Ph.D. from Fordham University, an M.A. from the University of WisconsinMadison, and a B.A. from Marquette University. His research has covered many areas, with the primary emphasis on Strategic Management. He has published articles in The Case Journal and the Indian Journal of Economics and Business, he co-edited the book Emerging Business Theories for Educators and Practitioners (2007), and he is the author of the book Rock and Roll and the American Landscape: The Birth of an Industry and the Expansion of the Popular Culture (2009). srosenbe@ monmouth.edu 
Dr. Joseph B. Mosca, Associate Professor of Management in the Leon Hess Business School at Monmouth University, earned his doctorate at NYU. Dr. Mosca specializes in Human Resource management, Human Relations, and active teaching methods, and is the recipient of seven teaching awards and three distinguished paper awards. His current research interests focus on developing hybrid courses, employee behavior, and jobs in the $21^{\text {st }}$ Century. mosca@monmouth.edu

\section{REFERENCES}

1. Alas, R. 2007. Reactions to Organizational Change from the Institutional Perspective: The Case of Estonia. Problems and Perspectives in Management 5 (3): 19-31.

2. $\quad$ Armenakis, A.A., S.G. Harris, and H.S. Field. 1999. Making Change Permanent: A Model for Institutionalizing Change Interventions. In W. Passmore and R. Woodman (Eds.), Research in Organizational Change and Development Vol. 12, pp. 289-319. Greenwich, CT: JAI Press.

3. Barczak, G, C. Smith, and D. Wilemon. 1987. Managing Large-Scale Organizational Change. Organizational Dynamics 16 (2): 22-35.

4. Bordum, A. 2010. The Strategic Balance in a Change Management Perspective. Society and Business Review 5 (3): 245-258.

5. Brunninge, O. 2009. Using History in Organizations: How Managers Make Purposeful Reference to History in Strategy Processes. Journal of Organzational Change Management 22 (1): 8-26.

6. Connor, D.R. 1993. Managing at the Speed of Change: How Resilient Managers Succeed and Prosper Where Others Fail. New York: Villard Books.

7. $\quad$ David, F.R. 2006. Strategic Management: Concepts and Cases $\left(11^{\text {th }}\right.$ ed.). Upper Saddle River, NJ: Prentice-Hall.

8. $\quad$ Denning, S. 2005. Transformational Innovation. Strategy \& Leadership 33 (3): 11-16.

9. Eaton, M. 2010. Making Improvements Stick: The Importance of People over Process. Human Resource Management International Digest 18 (5): 30-35.

10. Getz, G., C. Jones, and P. Loewe. 2009. Migration Management: An Approach for Improving Strategy Implementation. Strategy \& Leadership 37 (6): 18-24.

11. Gill, R. 2003. Change Management- Or Change Leadership. Journal of Change Management 3 (4): $307-$ 321.

12. Gilley, A., M. Godek, and J. Gilley. 2009. Change, Resistance, and the Organizational Immune System. S.A.M. Advanced Management Journal 74 (4): 4-10.

13. Habeck, M.M., F. Kroger, and M.R. Tram. 2000. After the Merger: Seven Rules for Successful Post-Merger Integration. Harlow, UK: Financial Times/Prentice-Hall.

14. Haveman, H.A. 1993. Organizational Size and Change: Diversification in the Savings and Loan Industry after Deregulation. Administrative Science Quarterly 38 (1): 20-50.

15. He, H. and Y. Baruch. 2009. Transforming Organizational Identity under Institutional Change. Journal of Organization Change Management 22 (6): 575-599.

16. Hultman, K.E. 1995. Scaling the Wall of Resistance. Training and Development (October): 15-18.

17. Karim, A. and Y. Kathawala. 2005. The Experience of Manufacturing Firms with the Implementation of Different Production Philosophies: A United States Survey. International Journal of Management 22 (3): 351-365.

18. Kesler, G. and A. Kates. 2010. Designing Strategic Organizations: The New Work of Executives and HR. People and Strategy 33 (3): 14-21.

19. Kotter, J.P. 1996. Leading Change. Boston: Harvard Business School Press.

20. Levin, I. and J. Gottlieb. 2009. Realigning Organization Culture for Optimal Performance: Six Principles \& Eight Practices. Organization Development Journal 27 (4): 31-46.

21. Lewin, K. 1951. Field Theory in Social Science. New York: Harper.

22. Maurer, R. 2010. Applying What We've Learned About Change. The Journal for Quality and Participation 33 (2): $35-38$.

23. McGuire, J.B. and G.B. Rhodes. 2009. Transforming Your Leadership Culture. San Francisco: JosseyBass.

24. $\quad$ Rogers, E.M. 2003. Diffusion of Innovations ( $5^{\text {th }}$ ed.). New York: The Free Press.

25. $\quad$ Schaffer, R. 2010. "Four Mistakes Leaders Keep Making.” Harvard Business Review 88 (9): 86-127. 
26. Self, D.R., and M. Schraeder. 2009. Enhancing the Success of Organizational Change: Matching Readiness Strategies with Sources of Resistance. Leadership \& Organization Development Journal 30 (2): 167-182.

27. Sims, R.R. 2002. Employee Involvement is Still the Key to Successfully Managing Change. In S.J. Sims and R.R. Sims (Eds.), Changing the Way we Manage Change, pp. 33-54. Wesport, CT: Quorum.

28. Sparrow, O. and G. Ringland. 2010. A System for Continuous Organizational Renewal. Strategy \& Leadership 38 (4): 34-41.

29. Trader-Leigh, K.E. 2002. Identifying Resistance in Managing Change. Journal of Organizational Change Management 15 (2): 138-156.

30. Werkman, R.A. 2009. Understanding Failure to Change: A Pluralistic Approach and Five Patterns. Leadership \& Organization Development Journal 30 (7): 664-684.

31. Zorn, T.E., L.T. Christensen, and G. Cheney. 1999. Do We Really Want Constant Change? San Francisco: Berrett-Koehler. 